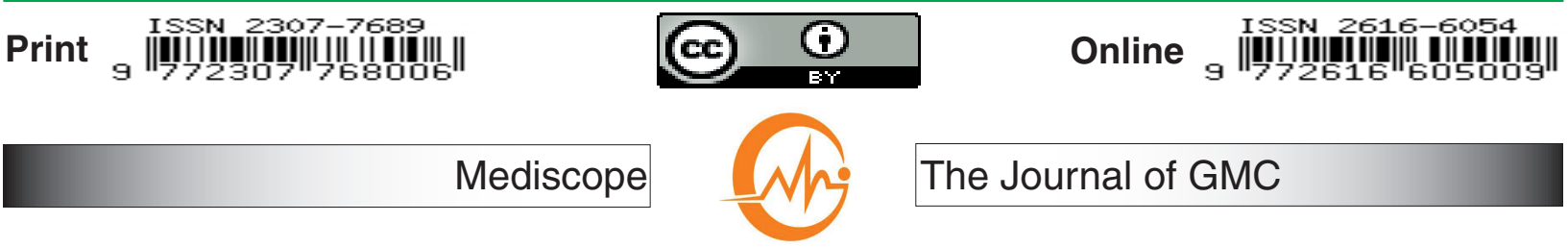

\title{
Impact of smartphone use on health among higher secondary level students in Khulna, Bangladesh
}

\author{
S Chowdhury ${ }^{1 凶}$, BK Basu $^{2}$, MS Laskar $^{3}$
}

\begin{abstract}
Smartphone is used worldwide even by students as a very much necessary electronic device. The present study aimed at finding out any impact of smartphone use on health of higher secondary certificate level students in Khulna, Bangladesh using a semi-structured questionnaire, which included different socioeconomic characteristics such as social status, duration of smartphone use, related possible health problems like eye strain, headache, hearing problem, sleep disturbance and depression. Three hundred seventy students participated in this study. The modes of using smartphone by the students were: no use, audio calls, video calls, gamming, chatting, facebooking, and taking photo. The students were $40.5 \%$ of $11^{\text {th }}$ level and $59.5 \%$ of $12^{\text {th }}$ level, $42.2 \%$ of age $<17$ years, $43.8 \%$ males, $76.8 \%$ came from urban schools, $84.9 \%$ with science background, $35.7 \%$ had family members $>4,65.1 \%$ had parents with higher social status, $89.7 \%$ used smartphone, and $34.6 \%$ used with daily duration $>1$ hour. The smartphone use was significantly associated with sleep disturbance $(p<0.05)$ as an expression of health impact. The symptom sleep disturbance significantly associated with other reported symptoms by the respondents like eye strain, headache, hearing problem, and depression. All the symptoms were positively and significantly inter-related $(p<0.05$ or $p<0.01)$. Smartphone should be used with a cautious manner, as there might be a chance to develop health related symptoms. Key words: smartphone use, health impact, college students, Bangladesh.
\end{abstract}

\section{Introduction}

Mobile phone is a wonderful invention of modern science. With the passage of time, it has become a very necessary electronic device. Modern globalized people of present world think themselves helpless without having it. Perhaps it is the easiest medium of communication for them around the world. The people are communicating using smartphone, becoming faster and want newer technology. So, mobile is getting smarter day by day. Smartphone now is an object, which has become a passion for most of the people.

Smartphone is providing various types of apps, which are fulfilling multipurpose demand of young generation. They get the whole world on a small screen. The young generation has also taken smartphone as a source of recreation. Young people are now so addicted to their mobile phones that it feels like they have lost a limb when they are without them. ${ }^{1,2}$ They spent their leisure time

\footnotetext{
1. S Chowdhury, MS, Assistant Professor, Department of English, Government Majid Memorial City College, Khulna. Email: chowdhuryshima2017@gmail.com

2. BK Basu, MD, CO, PhD, Associate Professor of Surgery, Gazi Medical College, Khulna

3. MS Laskar, MD, MPH, PhD, Professor (cc) \& Head, Department of Community Medicine, Gazi Medical College, Khulna
} 
mostly with their smartphones.

The higher secondary certificate (HSC) level students in Bangladesh are also frequent users of smartphone, and almost every student belongings to HSC level whether in urban or rural area has a smartphone. They are fond of different types of apps such as audio, video, chatting, gamming, facebooking, taking photo, etc. They take the device as a good company. The fascination for mobile is so strong that sometimes they hide the things from their parents. Instead of studying, they become busy on screen. On the other hand, they sleep at night less than necessary. As the screen of smartphone remains very near to eye, it may cause various discomforts concerning eye. That means, the students may have health problems due to use of smartphone. ${ }^{2}$ The present study aimed to find out the possible health effects of smartphone use on students.

\section{Materials and Method}

The study conducted over a period of two months (May - June 2018) using semistructured questionnaire for data collection. The questionnaire included different socioeconomic characteristics such as social status, duration of smartphone use, related possible health problems like eye strain, headache, hearing problem, sleep disturbance and depression. The questionnaires were distributed among college students of $11^{\text {th }}$ and $12^{\text {th }}$ level studying in different colleges of Khulna city who were voluntarily willing to participate in the present study after a discussion about the study.

The students of different groups (arts, commerce and science) were requested to respond to the questions of the questionnaire. This was done during the interval of the classes so that the teaching session would not hamper. It was ensured to the students that no harm would occur to them for revealing facts, rather it would be used only for research purpose.

The collected data were entered into a computer and were analyzed using the Statistical
Package for the Social Sciences (SPSS) version $22 .{ }^{3}$ A $p$ value of $<0.05$ was considered significant.

\section{Results}

Three hundred seventy students participated in this study. The Fig. 1 shows the modes of using smartphone by the students (no use, audio calls, video calls, gamming, chatting, facebooking, and taking photo). Among the students, $10.3 \%$ did not use any smartphone, and from other six modes, $45.1 \%$ used for one mode, $6.8 \%$ two modes, $5.1 \%$ three modes, $3.0 \%$ four modes, $2.7 \%$ five modes and $27.0 \%$ six modes.

Table 1 shows the socio-demographic characteristics of the respondents. The students were $40.5 \%$ of $11^{\text {th }}$ level and $59.5 \%$ of $12^{\text {th }}$ level, $42.2 \%$ of age $<17$ years, $43.8 \%$ males, $76.8 \%$ came from urban schools, $84.9 \%$ with science background, $75.1 \%$ had Grade Point Average (GPA) 5 in Secondary School Certificate (SSC) level, $35.7 \%$ had family members $>4,65.1 \%$ had parents with higher social status, $89.7 \%$ used smartphone, and $34.6 \%$ used with daily duration $>1$ hour.

Table 2 presents the crosstab for smartphone use and symptoms reported by the respondents. Chi-square test revealed that the smart phone use was significantly associated with sleep disturbance $(p<0.05)$ as an expression of health impact.

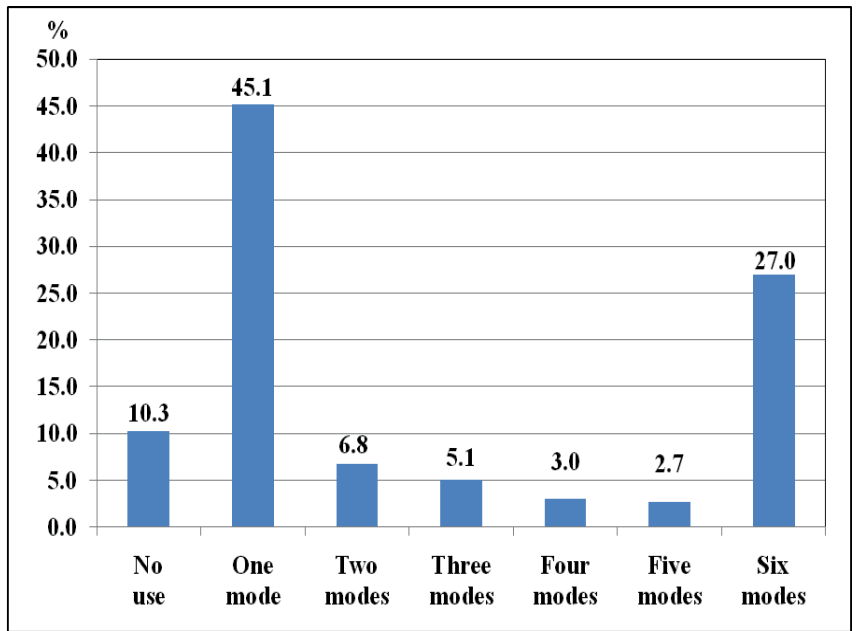

Fig. 1. Way of using smartphone (modes: no use, audio calls, video calls, gamming, chatting, facebooking, taking photo), $n=370$. 
Table 1. Socio-demographic characteristics of the respondents, $n=370$

\begin{tabular}{|c|c|c|}
\hline Characteristics & $\mathbf{n}$ & $\%$ \\
\hline \multicolumn{3}{|l|}{ Class level } \\
\hline $11^{\text {th }}$ & 150 & 40.5 \\
\hline $12^{\text {th }}$ & 220 & 59.5 \\
\hline \multicolumn{3}{|l|}{ Age (years) } \\
\hline$<17$ & 156 & 42.2 \\
\hline$\geq 17$ & 214 & 57.8 \\
\hline \multicolumn{3}{|l|}{ Gender } \\
\hline Male & 162 & 43.8 \\
\hline Female & 208 & 56.2 \\
\hline \multicolumn{3}{|c|}{ Secondary school location } \\
\hline Urban & 284 & 76.8 \\
\hline Rural & 86 & 23.2 \\
\hline \multicolumn{3}{|l|}{ Academic group } \\
\hline Science & 314 & 84.9 \\
\hline Arts & 11 & 3.0 \\
\hline Commerce & 45 & 12.2 \\
\hline \multicolumn{3}{|c|}{ GPA at Secondary School Certificate } \\
\hline$<5$ & 92 & 24.9 \\
\hline$=5$ & 278 & 75.1 \\
\hline \multicolumn{3}{|c|}{ Number of family members } \\
\hline$\leq 4$ & 238 & 64.3 \\
\hline$>4$ & 132 & 35.7 \\
\hline \multicolumn{3}{|c|}{ Parental social status } \\
\hline Lower & 129 & 34.9 \\
\hline Higher & 241 & 65.1 \\
\hline \multicolumn{3}{|l|}{ Smartphone use } \\
\hline Did not use & 38 & 10.3 \\
\hline Used & 332 & 89.7 \\
\hline \multicolumn{3}{|c|}{ Duration of daily use (hour) } \\
\hline 0 & 38 & 10.3 \\
\hline$\leq 1$ & 204 & 55.1 \\
\hline$>1$ & 128 & 34.6 \\
\hline
\end{tabular}

n, number.

Table 3 shows the Pearson correlations of sleep disturbance with other reported symptoms by the respondents like eye strain, headache, hearing problem, and depression. All the symptoms were positively and significantly inter-related $(p<0.05$ or $p<0.01)$.

\section{Discussion}

The present study aimed at finding out any impact of smartphone use on health of HSC level students in Khulna, Bangladesh using a semi-structured questionnaire, which included different socioeconomic characteris- 
Table 2. Crosstab for smartphone use and reported symptoms, $\mathbf{n}=\mathbf{3 7 0}$

\begin{tabular}{lrrrr}
\hline & & Smart phone used & Did not use & p value* \\
& & $n$ & $n$ & \\
\hline \multirow{2}{*}{ Eye strain } & Yes & 25 & 13 & \multirow{2}{*}{ No } \\
Headache & Yes & 224 & 109 & $>0.05$ \\
& No & 22 & 16 & \\
& Yes & 147 & 185 & $>0.05$ \\
Hearing problem & No & 37 & 1 & $>0.05$ \\
& Yes & 299 & 33 & \\
Sleep disturbance & No & 33 & 5 & $<0.05$ \\
& Yes & 232 & 100 & \\
\hline \multirow{2}{*}{ Depression } & No & 21 & 17 & $>0.05$ \\
& 160 & 172 & & \\
\hline
\end{tabular}

n, number. *: Chi-square or Fisher's exact test.

Table 3. Pearson correlations of sleep disturbance with other reported symptoms, $\mathbf{n}=\mathbf{3 7 0}$

\begin{tabular}{|c|c|c|c|c|c|}
\hline & $\begin{array}{l}\text { Eye } \\
\text { strain }\end{array}$ & Headache & $\begin{array}{l}\text { Hearing } \\
\text { problem }\end{array}$ & $\begin{array}{c}\text { Sleep } \\
\text { disturbance }\end{array}$ & Depression \\
\hline Eye strain & 1.000 & & & & \\
\hline Headache & $0.281^{* *}$ & 1.000 & & & \\
\hline Hearing problem & $0.117^{*}$ & $0.217^{* *}$ & 1.000 & & \\
\hline Sleep disturbance & $0.149^{* *}$ & $0.168^{* *}$ & $0.236^{* *}$ & 1.000 & \\
\hline Depression & $0.117^{*}$ & $0.134^{* *}$ & $0.162^{* *}$ & $0.160^{* *}$ & 1.000 \\
\hline
\end{tabular}

tics such as social status, duration of smart phone use, related possible health problems like eye-strain, headache, hearing problem, sleep disturbance and depression. The modes of using smartphone by the students were: no use, audio calls, video calls, gamming, chatting, facebooking, and taking photo.

The smartphone use was significantly associated with sleep disturbance as an expression of health impact. The symptom sleep disturbance significantly associated with other reported symptoms by the respondents like eye strain, headache, hearing problem, and depression. All the symptoms were positively and significantly inter-related. It was reported in a study evaluating the possible psychological problems related to excessive cellular phone use in adolescents that the potentially excessive user group had a tendency to identify themselves with their cellular phones and to have difficulties in controlling usage. ${ }^{4}$ They expressed more depressive symptoms, higher interpersonal anxiety, and lower self-esteem. ${ }^{4} \mathrm{~A}$ positive correlation was also observed between excessive cellular phone use and Internet addiction. ${ }^{4,5}$ Another study reported that smartphone use/texting was negatively related to GPA and positively related to anxiety; in turn, GPA was positively related to satisfaction with life while anxiety was negatively related to satisfaction with life. ${ }^{6}$ These findings add to the debate about student smartphone use, and how increased use may negatively impact academic performance, mental health, and subjective well-being or happiness. ${ }^{6}$

The present study among HSC level students revealed the fact that smartphone 
use has a negative impact on their health. The HSC level has students who have to face a high-level academic stress. They are to complete an elaborate syllabus within a short duration of time. Be with smartphone frequently lessens their study hour. Smartphone users spend a lot of time on their phone compelling to reduce their face-toface contact time making them sometime lonely. Sometimes, they curtail their sleeping hours to use smartphone, which might affect their health. Therefore, smartphone should be used with a cautious manner, as there might be a chance to develop health related symptoms.

\section{References}

1. The Telegraph, United Kingdom. The young generation are 'addicted' to mobile phones. Available on https://www.telegra ph.co.uk/technology/8458786/The-young -generation-are-addicted-to-mobile-phon es.html (accessed on August 15, 2018).

2. Chowdhury S. Facebook and smart phone costing a lot. The Daily Observer. Available on http://epaper.observerbd.com/2017/11/1 5/6/details/6_r4_c2.jpg (accessed on August 15, 2018).

3. SPSS Inc. SPSS for Windows Computer software (version SPSS 22). Chicago, IL, USA; 2002.

4. Ha JH, Chin B, Park DH, Ryu SH, Yu J. Characteristics of excessive cellular phone use in Korean adolescents. Cyberpsychol Behav 2008;11(6):783-4.

5. Kandell JJ. Internet addiction on campus: the vulnerability of college students. Cyberpsychol Behav 1998;1(1):11-7

6. Lepp A, Barkley JE, Karpinski AC. The relationship between cell phone use, academic performance, anxiety, and satisfaction with life in college students. Comput Human Behav 2014;31:343-50.

Suggestion for citation of the above:

Chowdhury S, Basu BK, Laskar MS. Impact of smartphone use on health among higher secondary level students in Khulna, Bangladesh. Mediscope 2019;6(1):1-5. 